\title{
Parvovirus associated aplastic crisis in homozygous sickle cell disease
}

\author{
A R GOLDSTEIN, M J ANDERSON, AND G R SERJEANT \\ Medical Research Council Laboratories (Jamaica), University of the West Indies, Kingston, Jamaica, and \\ Department of Medical Microbiology, University College Hospital, London
}

SUMMARY Aplastic crises in homozygous sickle cell disease in Jamaica predominantly affect children and occur in epidemics. Of 67 cases in a cohort study of 314 children with homozygous sickle cell disease, 62 were attributable to human parvovirus infection. Affected children were aged $0 \cdot 5-12.5$ years, and the incidence rose to $28 \%$ by 10 years. No recurrences were seen. Symptoms and signs on presentation were attributable to the viraemia and acute anaemia. Asymptomatic thrombocytopenia was common. Blood transfusion was given in 54 cases $(87 \%)$. Thirty eight children (61\%) were admitted to hospital, 16 of whom were extremely ill on presentation and one of whom died soon after admission. Twenty four (39\%) were managed as outpatients, 16 of whom were transfused. Parvovirus associated aplastic crisis is a self limited condition with excellent prognosis if diagnosed promptly and managed appropriately.

The aplastic crisis occurs in a variety of chronic haemolytic conditions. ${ }^{1-4} \mathrm{~A}$ temporary stopping of erythropoiesis is followed by a rapid fall in haemoglobin concentration, and death may result from peripheral circulatory failure. Most episodes are associated with human parvovirus infection. ${ }^{35-8}$ Of 67 aplastic crises in a cohort study of sickle cell disease, 62 were attributable to parvovirus infection.

\section{Patients and methods}

Three hundred and fourteen children with homozygous sickle cell disease were identified during the screening of 100000 consecutive babies at the main Government Maternity Hospital (Victoria Jubilee Hospital) between 1973 and 1981. These children are being prospectively followed up in a cohort study and the methods of diagnosis," follow up, and haematological investigations ${ }^{90}$ have been described previously.

The aplastic crisis was defined as a fall in haemoglobin markedly below steady state values associated with absence of or very few $(\leqslant 1 \%)$ reticulocytes in the peripheral blood. With higher concentrations of reticulocytes, the diagnosis was only accepted if there was a daily increase consistent with the recovery phase of the aplastic crisis. These haematological criteria were met in 67 children, of whom 62 had evidence of concurrent parvovirus infection. The diagnosis of recent parvovirus infection was based on the finding of viral deoxyribonucleic acid (DNA) in acute serum samples (16 cases), parvovirus specific IgM in acute or convalescent serum samples (27), or seroconversion (19).

Fifty four children presented to special cohort clinics and eight to the casualty department.

\section{Results}

Three epidemics of aplastic crisis occurred during the study-namely, in 1973-75, 1979-80, and 198486. No aplastic crises were seen between these epidemics. One, 24 , and 37 cohort children were affected in the three epidemics, respectively, representing an overall prevalence of $20 \%$ and an incidence of $28 \%$ by 10 years. The youngest child was 0.5 years and four were affected in the first year. Sexes were affected equally ( 35 boys and 27 girls).

Clinical features. A prodromal illness was reported in 61 children, one episode being diagnosed retrospectively during a routine blood test. The prodrome averaged two to three days (range one to 14 days), and the prodromal symptoms are listed in Table 1.

The major signs on examination are summarised in Table 2. The oral temperature, measured in 54 children, was $37 \cdot 1-38^{\circ} \mathrm{C}$ in $19(35 \%)$ and exceeded $38^{\circ} \mathrm{C}$ in $23(43 \%)$. Splenomegaly increased in size in 
Table 1 Prodromal symptoms in 62 aplastic crises

\begin{tabular}{ll}
\hline Symptoms & $\begin{array}{l}\text { No }(\%) \text { with } \\
\text { that symptom }\end{array}$ \\
\hline Fever & $42(68)$ \\
Headache & $22(35)$ \\
Abdominal pain & $20(32)$ \\
Upper respiratory infection & $18(29)$ \\
Anorexia & $14(23)$ \\
Limb pains & $13(21)$ \\
Vomiting & $9(15)$ \\
Pallor & $9(15)$ \\
Weakness & $8(13)$ \\
Breathlessness & $3(5)$ \\
\hline
\end{tabular}

Table 2 Major signs on examination in 62 aplastic crises

\begin{tabular}{|c|c|}
\hline Sign & $\begin{array}{l}\text { No }(\%) \text { with } \\
\text { that sign }\end{array}$ \\
\hline Pallor & $54(87)$ \\
\hline Tachycardia & $23(37)$ \\
\hline Hepatomegaly $(3 \mathrm{~cm})$ & $13(21)$ \\
\hline Gallop rhythm & $10(16)$ \\
\hline Pharyngitis & $9(15)$ \\
\hline Otitis media & $6(10)$ \\
\hline Chest signs & $4(6)$ \\
\hline Confusion & $4 \quad(6)$ \\
\hline Neck stiffness & $3 \quad(5)$ \\
\hline Dehydration & $3 \quad(5)$ \\
\hline
\end{tabular}

four children (aged 0.6-3.6 years), all of whom had evidence of heart failure. A macular rash on face and trunk occurred one week before aplasia in a child aged 7.5 years, and another aged 6 years had generalised pruritis but without a rash at presentation.

Familial involvement was common, aplastic crises developing in six of nine siblings with homozygous sickle cell disease of affected children at intervals of seven to 32 days after the index case.

A girl aged 5.3 years had the simultaneous occurrence of parvovirus infection and salmonella septicaemia. She was ill and drowsy at presentation with only a slight pallor, and her platelet count was 100000 above steady state. Her haemoglobin concentration had fallen from $9 \cdot 1$ to $6.2 \mathrm{~g} / \mathrm{dl}$ and reticulocyte count from $3 \%$ to $0 \cdot 8 \%$. A blood sample grew Salmonella St Paul but also manifested 60 arbitrary units of parvovirus specific IgM, confirming recent parvovirus infection.

Haematological investigations. Mean haemoglobin concentration at presentation was $3.9 \mathrm{~g} / \mathrm{dl}$ (range $1 \cdot 8-8.5 \mathrm{~g} / \mathrm{dl})$, representing an average fall of $3.9 \mathrm{~g} / \mathrm{dl}$ (range $1.7-6.9 \mathrm{~g} / \mathrm{dl}$ ), below the individual's steady state values. Reticulocytes were absent from the peripheral blood in 43 cases $(69 \%)$, between $0 \cdot 1$ and $1.0 \%$ in $14(23 \%)$, and between 6 and $25 \%$ in five, all of whom seemed to be in the recovery phase of the aplastic crisis. The return of reticulocytes-that is, recovery-was monitored in 38 of 57 patients who presented in the acute phase of the aplasia and occurred in one to three days in 11 children, four to six days in 11 , and seven to 10 days in 16 .

Mean cell volume at the time of aplasia was available in 60 of the 62 patients and was within $5 \mathrm{fl}$ of steady state values in $39(65 \%)$, fell in 12 , and rose in seven. Total serum bilirubin concentrations at the time of aplasia were available in 24 of the 62 patients and were unchanged $( \pm 5 \mu \mathrm{mol} / \mathrm{l})$ in five. In one patient the total bilirubin concentration increased from 34 to $48 \mu \mathrm{mol} / \mathrm{l}$, but 18 showed an average fall of $19 \mu \mathrm{mol} / 1$ (range 5-72 $\mu \mathrm{mol} / \mathrm{l}$ ).

Total white blood cell counts (total nucleated cell counts corrected for nucleated red cells) were available in 46 of the 62 patients and were within 2000 of previous steady state values in 10 . Counts fell in 22 patients, of whom 19 showed decreases of $3000-9000$ and three decreases of 12 000-17 000. Counts increased in 14 patients, of whom four had increases of 5000-9000 and 10 increases of 11000 45000 .

Platelet counts at the time of aplasia were measured in 37 children and were within 25000 of steady state in four. They fell in 27 children $(73 \%)$ by a mean of 201000 (range 62000-584 000) below steady state values and were below 150000 in four, although none had spontaneous bleeding. They increased in six children, two of whom were in the recovery phase of aplasia, one of whom had a cocomitant salmonella septicaemia, and three of whom had no explanation.

Fetal haemoglobin concentrations at the time of aplasia were measured in 25 children and did not deviate by more than $5 \%$ of previous steady state values in three patients. In 22 children fetal haemoglobin concentrations showed a mean proportional increase of $58 \%$ (range $10-133 \%$ ).

Serum iron concentrations at the time of aplasia were available in 20 children and were unchanged in two. The concentrations increased in 16 , often strikingly, the concentrations exceeding $36 \mu \mathrm{mol} / \mathrm{l}$ in seven and iron saturations exceeding $70 \%$ in eight. These concentrations generally fell precipitately with the recovery of erythropoiesis.

Management. A single transfusion of packed red cells was given in 54 children $(87 \%)$. Of the eight children not receiving transfusion, three were in the recovery phase, one refused on religious grounds, and four had only modest decreases in haemoglobin concentrations.

Blood cultures, performed in 48 cases $(77 \%)$, yielded one pathogen, a Salmonella St Paul spp. 
Cerebrospinal fluid was sterile in all six cases examined. Antibiotics were prescribed for possible bacterial infection in 44 children $(71 \%$ ) (seven cases of clinical pneumonia, five of tonsillitis or pharyngitis, four of otitis media, one of burns, and 27 of unexplained fever).

In the first two epidemics 22 of 25 patients $(88 \%)$ were admitted to hospital, but in the last epidemic only 16 of $37(43 \%)$ were admitted. Of these, eight presented late in the day or out of clinic hours and eight had complications (two had acute circulatory collapse, two had possible septicaemia, and one each had dehydration, painful crisis, pneumonia, and transfusion reaction). Only these eight $(22 \%)$ required admission for medical reasons. The changing attitude to admission to hospital reflected increased familiarity with the natural history, good prognosis with appropriate management, and increased use of outpatient transfusion and close follow up.

Outcome. One child died from circulatory collapse because an incorrect diagnosis in the casualty department led to a six hour delay in transfusion. The remaining 61 patients recovered uneventfully and none manifested recurrences.

\section{Discussion}

Chronic haemolytic anaemias are generally associated with expansion of bone marrow and a compensatory increase in erythropoetic activity. In the aplastic crisis there is a sudden and self limited stopping of marrow activity that predominantly affects erythroid maturation, which results in an absence, or very few immature red cells (normoblasts or reticulocytes) in the peripheral blood. In chronic haemolytic processes, because of the short survival of red cells, these events are rapidly reflected in the peripheral blood and manifest by a rapid fall in haemoglobin concentration. Such aplastic crises have been recognised in a variety of chronic haemolytic anaemias. ${ }^{1-4}$

It is vital to distinguish aplastic crises from hypoplastic episodes, which may attend certain infections (salmonella, pneumococcus, and mycoplasma), metabolic disturbances (renal failure), or nutritional abnormalities (folate deficiency). All may be associated with a lower reticulocyte count (1-5\%) and haemoglobin concentration (usually 4-6 $\mathrm{g} / \mathrm{dl}$ ) compared with steady state values. When clearly defined (as proposed in this paper) the aplastic crisis emerges as a separate entity that, in most episodes, is associated with human parvovirus infection.

In Jamaica aplastic crises follow a clear epidemic pattern with a four year interval between peaks, individual epidemics usually lasting 18-24 months. Human parvovirus infection accounted for 62 of 67 (93\%) episodes, and although no cause was found for the other five episodes, it is of interest that they occurred during the parvovirus related epidemics. Other causes of aplasia are reported ${ }^{11}$ and occasional combined infections may occur. ${ }^{12}$ Children with homozygous sickle cell disease do not seem to be more prone to parvovirus infection and this infection does not always result in clinically recognised aplasia. ${ }^{6}$ Clarification of the temporal relation between parvovirus infection and aplastic crises must await sero-epidemiological studies already underway.

The mechanisms of parvovirus induced aplasia have been discussed elsewhere. ${ }^{1314}$ Experimental human parvovirus infection of normal volunteers resulted in disappearance of reticulocytes, a fall in white blood cell and platelet counts, but only a slight fall in haemoglobin concentration. ${ }^{15}$ These features are all apparent in parvovirus related aplasia in homozygous sickle cell disease, although the haemoglobin fall is more pronounced because of the short survival of red cells. There is also a fall in bilirubin, a rise in serum iron, and a striking increase in fetal haemoglobin because of the greater survival of cells containing high amounts of fetal haemoglobin. These findings are diagnostic of the aplastic crisis and bone marrow examination is rarely necessary.

The clinical features are consequent on these haematological changes and the profound anaemia requires urgent blood transfusion. Other complications may necessitate admission to hospital, but in uncomplicated cases the predictable natural history and uniformly good prognosis generally allow outpatient management. Bone marrow activity returns spontaneously usually after a period of eight to 10 days and a pronounced reticulocytosis is associated with a rapid return to steady state haemoglobin concentrations. ${ }^{16}$ Patients should continue to be monitored during this period as a slower response may indicate superimposed iron or folate deficiency. Siblings with homozygous sickle cell disease should be watched for aplasia, because of the familial tendency and cross infection that may occur in the hospital ward. ${ }^{17}$

Skin changes are of particular interest because human parvovirus seems to be responsible for the maculopapular rash of erythema infectiosum,,${ }^{18}$ and a similar rash occurred in inoculated human volunteers. They are rarely recorded in human parvovirus related aplasia in sickle cell disease, although they did occur in one case in the present study. The reasons for this different behaviour are unknown.

Aplastic crises rarely, if ever, recur. Recurrent parvovirus related aplasias have never been re- 
ported and life long immunity seems to follow infection. A human parvovirus vaccine currently under development may therefore be effective in preventing this complication.

\section{References}

1 Singer K, Motulsky AG, Wile SA. Aplastic crisis in sickle cell anemia. J Lab Clin Med 1950;35:721-36.

2 Kelleher JF, Luban NLC, Mortimer PP, Kamimura T. Human serum "parvovirus". A specific cause of aplastic crisis in children with hereditary spherocytosis. J Pediatr 1983:102: 720-2.

$\checkmark$ Rao KRP. Patel AR. Anderson MJ. Hodgson J. Jones SE, Pattison JR. Infection with parvovirus-like virus and aplastic crisis in chronic hemolytic anemia. Ann Intern Med 1983;98:930-2.

${ }^{+}$Duncan JR. Potter CG. Cappellini MD, et al. Aplastic crisis due to parvovirus infection in pyruvate kinase deficiency. Lancet 1983:i:14-6.

5 Pattison JR. Jones SE. Hodgson J. Parvovirus infections and hypoplastic crisis in sickle cell anaemia. Lancet 1981;i:664-5.

- Serjeant GR. Topley JM. Mason K. et al. Outbreak of aplastic crisis in sickle cell anacmia associated with parvovirus-like agent. Lancet 1981:i:595-8.

7 Anderson MJ, David LR. Hodgson J, et al. Occurrence of infection with a parvovirus-like agent in children with sickle cell anaemia during a two-year period. J Clin Pathol 1982:35:744-9.

" Kelleher JF. Luban NLC. Cohen BJ. Mortimer PP. Human serum parvovirus as the cause of aplastic crisis in sickle cell discase. A m J Dis Child 1984:138:401-3.

"Serjeant BE, Forbes M, Williams LL. Serjeant GR. Screening cord bloods for the detection of sickle cell disease in Jamaica. Clin Chem 1974:20:666-9.

11 Serjeant GR. Grandison Y, Lowrie Y, et al. The development of hacmatological changes in homozygous sickle cell disease: a cohort study from birth to 6 years. Br J Haematol 1981;48: 533-43.

"Megas H. Papadiki E, Constantinides B. Salmonella septicacmia and aplastic crisis in patients with sickle cell anaemia. Acta Paediatr Scand 1961;50:517-21.

12 Brownell AI, McSwiggan DA, Cubitt WD, Anderson MJ. Aplastic and hypoplastic episodes in sickle cell disease and thalassacmia intermedia. J Clin Pathol 1986;39:121-4.

13 Young N. Mortimer PP. Viruses and bone marrow failure. Blood 1984:63:729-37.

14 Young $\mathrm{N}$. In vitro studies of human parvovirus and bone marrow cells. In: Pattison JR. Human parvovirus and disease. Boca Raton. Florida: CRC Press.

15 Anderson MJ, Higgins PG, Davis LR, et al. Experimental parvovirus infection in humans. J Infect Dis 1985;152:257-65.

16 MacIver JE, Parker-Williams EJ. The aplastic crisis in sickle-cell anacmia. Lancet $1961:$ i: 1086-9.

17 Evans JPM. Rossiter MA. Kumaran TO. Marsh GW. Human parvovirus aplasia: case due to cross infection in a ward. $\mathrm{Br}$ Med J 1984:288:681.

1s Anderson MJ, Jones SE. Fisher-Hoch SP. et al. Human parvovirus, the case of erethema infectiosum (fifth disease)? Lancet 1983;i:1378.

Correspondence to Professor G R Serjeant, Medical Research Council Laboratories, University of the West Indies, Kingston 7. Jamaica, West Indies.

Received 18 December 1986 